\title{
THE HUMAN PROSTATIC CANCER CELL LINE LNCaP AND ITS DERIVED SUBLINES: AN IN VITRO MODEL FOR THE STUDY OF ANDROGEN SENSITIVITY
}

\author{
G. J. van Steenbrugge, ${ }^{1 *}$ C. J. C. van Uffelen, ${ }^{1}$ J. Bolt ${ }^{2}$ and F. H. SChröDeR ${ }^{1}$ \\ Departments of ${ }^{1}$ Urology and ${ }^{2}$ Endocrinology and Reproduction, Erasmus University Rotterdam, \\ Rotterdam, The Netherlands
}

\begin{abstract}
Summary-The LNCaP-FGC (fast growing colony) cell line, a subline derived from the $\mathrm{LNCaP}$ cell line, shares all the main characteristics, including its androgen sensitivity, described for the parental line. A number of sublines originating from the FGC line were characterized with respect to their response to steroid-depleted medium and to the synthetic androgen R1881. The growth of FGC cells in DCC medium with $0.1 \mathrm{nM}$ R1881 was stimulated 2-3-fold compared to growth in DCC medium only. FGC cells that were continuously grown in DCC medium did not die, but their growth rate was clearly slowed down, and the cells remained responsive to androgen. These cells, therefore, have the androgen-sensitive, rather than the androgen-dependent phenotype. As cells of the subline FGC-JB could not be maintained in DCC medium, these cells better represent the androgendependent cell type. In contrast to the FGC line, cells of the R line, grew equally well in medium with complete or DCC serum. Under none of these culture conditions, R cells could significantly be stimulated further with R1881. Further analysis of the LNCaP-FGC sublines should provide valuable information concerning the development of androgen resistance in human prostate cancer.
\end{abstract}

\section{INTRODUCTION}

The origin of prostatic tumors is assumed to be monoclonal [1], but during tumor growth and progression, a diversity arises among the tumor cells [2]. This process is accompanied by a progression from a steroid-sensitive to steroidinsensitive state [3]. This presents a major problem in the clinical management of prostate cancer, because tumors can only effectively be treated with endocrine therapy while they remain androgen-sensitive [4, 5]. Studies with models for human breast cancer have shown that growth factors are involved in steroid regulation of breast cancer cell growth by both autocrine and paracrine mechanisms [6]. Steroid independence could result from uncoupled growth factor regulation by either constitutive secretion of a stimulatory factor or decreased secretion of an inhibitory factor [7].

A strong parallelism between androgenrelated prostate and estrogen-regulated breast

Proceedings of the VIIIth International Congress on Hormonal Steroids, The Hague, The Netherlands, $16-21$ September 1990.

*To whom correspondence should be addressed: Dr G. J. van Steenbrugge, Department of Urology (EE-1002), Division of Urological Oncology, P.O. Box 1738, 3000 DR Rotterdam, The Netherlands. cancer cell growth is very likely. The available information on androgen-mediated growth factor involvement in prostate cancer cell growth, however, is limited and is especially hampered by the lack of suitable model systems. Among the small number of permanent in vitro cell lines of human prostate cancer described up to now, the LNCaP (lymphe node carcinoma of the prostate) cell line, developed by Horoszewicz [8], is the only model with androgen responsive growth in vitro [9]. LNCaP cells secrete prostatic acid phosphatase and prostate specific antigen, the cells contain considerable amounts of androgen receptors, whereas estrogen and progesterone receptors are not detectable [10].

During the last few years, the LNCaP model has gained much interest. The LNCaP-FGC line, which is derived from an early passage of the original culture, has been distributed from the Roswell Park Memorial Institute over a large number of institutes, and it is also available through the American Type Culture Collection. This subline differs from the parental cell line (9) only by its growth rate. The $\mathrm{LNCaP}$ cells are shown to secrete polypeptide growth factors, such as epidermal growth factor (EGF) and transforming growth factor (TGF)- $\alpha$ [11] 
and, like androgens, EGF has been demonstrated to stimulate growth of the LNCaP cells [12]. The growth regulation of $\mathrm{LNCaP}$ cell by androgens and growth factors has been reviewed by Schuurmans et al. in a separate paper in this publication [13].

Propagation of LNCaP cell cultures led to the development of a number of sublines with different patterns of hormonal responsiveness. These sublines descended from the parental LNCaP line either spontaneously or by maintainance of the original cell line in medium with steroid-depleted serum. An example is the spontaneously emerged, androgen-insensitive LNCaP-r (resistant) subline, which was developed and further characterized by Hasenson et al. [14]. The present contribution describes the derivation and the major properties of the $\mathrm{LNCaP}$ sublines and some of the recent results obtained at our laboratory.

\section{EXPERIMENTAL}

\section{Cell lines}

The $\mathrm{LNCaP}$ cell line was derived from culture explants of needle biopsy material from a lymphe node metastases of a prostate cancer patient [8]. The arisen cultures could only be maintained by passing colonies of cells using the technique of microtransplantation over a period in excess of one year. These cultures ultimately resulted in a cell line, LNCaP, resembling a conventional cell culture, i.e. a line with a constant growth rate that could be subcultivated by enzymatic dispersion, as described in more detail by Horoszewicz et al. [8].

Figure 1 shows a schematic representation of the LNCaP cell line and its derived sublines as discussed in the present paper. The scheme also contains information on the current knowledge of the various sublines with respect to their androgen responsiveness. The $\mathrm{LNCaP}-\mathrm{FGC}$ cell line descended from a fast growing colony of the original $\mathrm{LNCaP}$ cultures, and thus is considered the reference LNCaP cell line. The FGC line was kindly made available to us by Dr Julius Horoszewicz (Buffalo, U.S.A.) and was transferred to our laboratory as a 16th passage culture.

The FGC-JB is a derivative of an early passage culture of the FGC. The LNO subline, also a gift from Dr Julius Horoszewicz, originated from cultures of an early (6th) passage of the parental line that was grown and subsequently maintained in medium with steroid-depleted serum (Horoszewicz; personal communication). The LNCaP- $r$ subline (designated ' $R$ ' in our laboratory), was kindly provided by $\mathrm{Dr}$ Hasenson (Huddinge, Sweden).

\section{Cell culture}

The cell lines FGC, FGC-JB and R were routinely maintained as monolayer cultures in RPMI medium (Gibco Europe, Breda, The Netherlands) supplemented with $10 \%$ fetal bovine serum (FBS; Boehringer, Mannheim, Fed. Rep. Germany, or Hyclone, Greiner, Alphen a/d Rijn, The Netherlands), $2 \mathrm{mM}$ glutamine and antibiotics. The LNO cultures were grown under the same conditions, except that the medium contained $5 \%$ dextran-coated charcoal (DCC; dextran $0.1 \%$, charcoal $1 \%$ )-treated (i.e. steroid-depleted) serum. Untreated (FBS) serum contained $0.5-1.0 \mathrm{nM}$ of testosterone (T), whereas in DCC serum less than $0.1 \mathrm{nM}$ of $\mathrm{T}$ (the detection limit of the assay) was estimated. All cell cultures were grown in plastic tissue culture flasks (Falcon, Oxnard, U.S.A.). Cultures were kept in a humidified atmosphere of $5 \% \mathrm{CO}_{2}$ in air, at a temperature of $37^{\circ} \mathrm{C}$. Cells

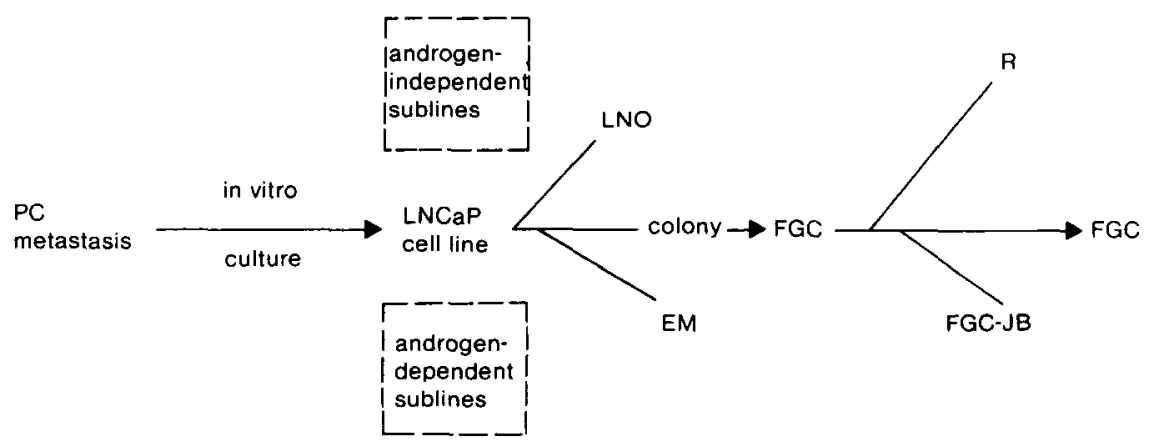

Fig. 1. Schematic representation of the $\mathrm{LNCaP}$ cell line and its descending sublines. EM: electron microscopically studied subline (cf. Ref. [8]); LNO: lymphe node original; FGC: fast growing colony; FGC-JB: FGC derivative; R (= LNCaP-r); LNCaP-(androgen)-resistant (cf. Ref. [14]). 
were subcultivated at weekly intervals using a mixture of $0.05 \%$ trypsin and $0.01 \%$ EDTA.

\section{Cell growth experiments}

The growth of the different cell lines under standard conditions, i.e. in medium with $10 \%$ FBS, was compared with their behavior when FBS was replaced by DCC serum. More specifically, the androgen responsiveness of the various cell types was determined with the synthetic, nonmetabolizable [15] androgen R1881 (New England Nuclear, Boston, MA, U.S.A.). Cells from stock cultures were plated at a density of $5.10^{5} / 25 \mathrm{~cm}^{2}$ flask and grown for 2 or 3 days in $5 \mathrm{ml}$ medium with DCC serum, whereafter the medium was replaced by medium containing DCC serum and R1881 in the range of $10^{-7}-10^{-11} \mathrm{M}$. Control cultures were grown in medium with $0.01 \%$ ethanol vehicle. Media were changed every other day. Cells were harvested at 5,6 or 8 days (see Results section) after the androgen was added and counted using a hemocytometer.

In some experiments the effects of DCC and R1881 treatment were evaluated with a test system based on the enzymatic reduction of the tetrazolium salt MTT [3-(4,5-dimethylthiazol-2yl)-2,5-diphenyl-tetrazoliumbromide] [16]. This proliferation assay was previously described to be suitable for the assessment of hormonestimulated growth of the LNCaP cell line [17]. After 3 days preincubation in DCC medium, cells were harvested, seeded in microtiter plates (Costar, Cambridge, MA, U.S.A.) at a concentration of 5000 per well, and reincubated for $24 \mathrm{~h}$ to allow for reattachment. Subsequently, the cells were exposed to experimental media for 5 days. Cells were pulsed with MTT, incubated for $4 \mathrm{~h}$ whereafter the plates were processed as described by Romijn et al. [17].

\section{RESULTS}

Effect of steroid-depleted serum on LNCaP growth

Cultures of FGC and LNO differ in their response to medium supplemented with either FBS or DCC serum, as illustrated in Fig. 2. Both types of cells were cultured in medium

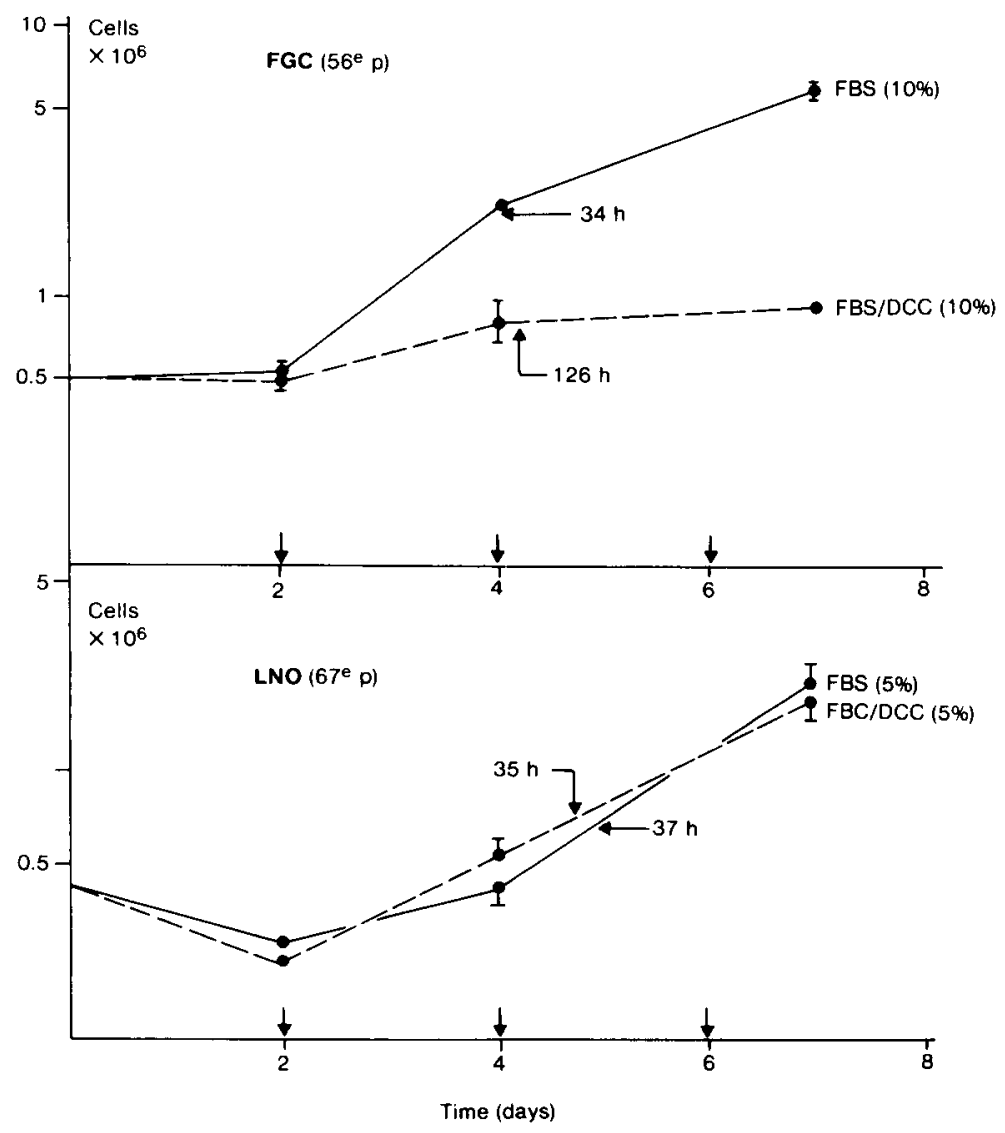

Fig. 2. Growth of FGC and LNO cells in complete (FBS) and in steroid-depleted (DCC) serum $\downarrow=$ medium change. 
with a serum percentage in which the respective cells were routinely propagated (see Experimental section). No difference was observed between the growth of the FGC cell in medium supplemented with 10 or $5 \%$ (FBS) serum (result not shown). After a lag phase of 2 days, FGC cells exponentially grew for the next 5 days, the doubling time being $34 \mathrm{~h}$, whereas during the same period of time in DCC medium the cells doubled only once (Fig. 2).

FGC cells that were continued to grow in DCC medium did not die, but clearly slowed down their growth rate, while the cells also showed morphological changes. Such cultures could be maintained for long periods of time and therefore were considered as being a separate LNCaP subline, designated FGC-DCC.

\section{Androgen responsiveness of the FGC line}

The ability of androgens (i.e. R1881) to stimulate growth of the FGC cells in the pres- ence of $5 \%$ DCC serum is shown in Fig. 3A. FGC cultures were preconditioned for 3 days by growing the cells in medium with $5 \%$ DCCmedium prior to harvesting and seeding the cells in microtiter plates for performing an MTT assay. Cells that were continued to grow for 5 days in DCC medium showed a 2.3 -fold increase in cell number, and could be further stimulated with R1881 (Fig. 3). In this particular experiment growth of FGC cells could significantly be stimulated ( 2.5 -fold) only with a concentration of $0.1 \mathrm{nM} \mathrm{R} 1881$, the level reached being similar to that of cells grown in control (FBS) serum.

FGC-DCC cells cultured for 3 months (i.e. 13 passages) in DCC medium were still sensitive for R1881, the pattern of response, however, was different from that of the parental FGC cells (cf. Fig. 3A and B). FGC-DCC cells were 4-fold stimulated after prolonged growth in DCC medium, and were maximally (2-fold)
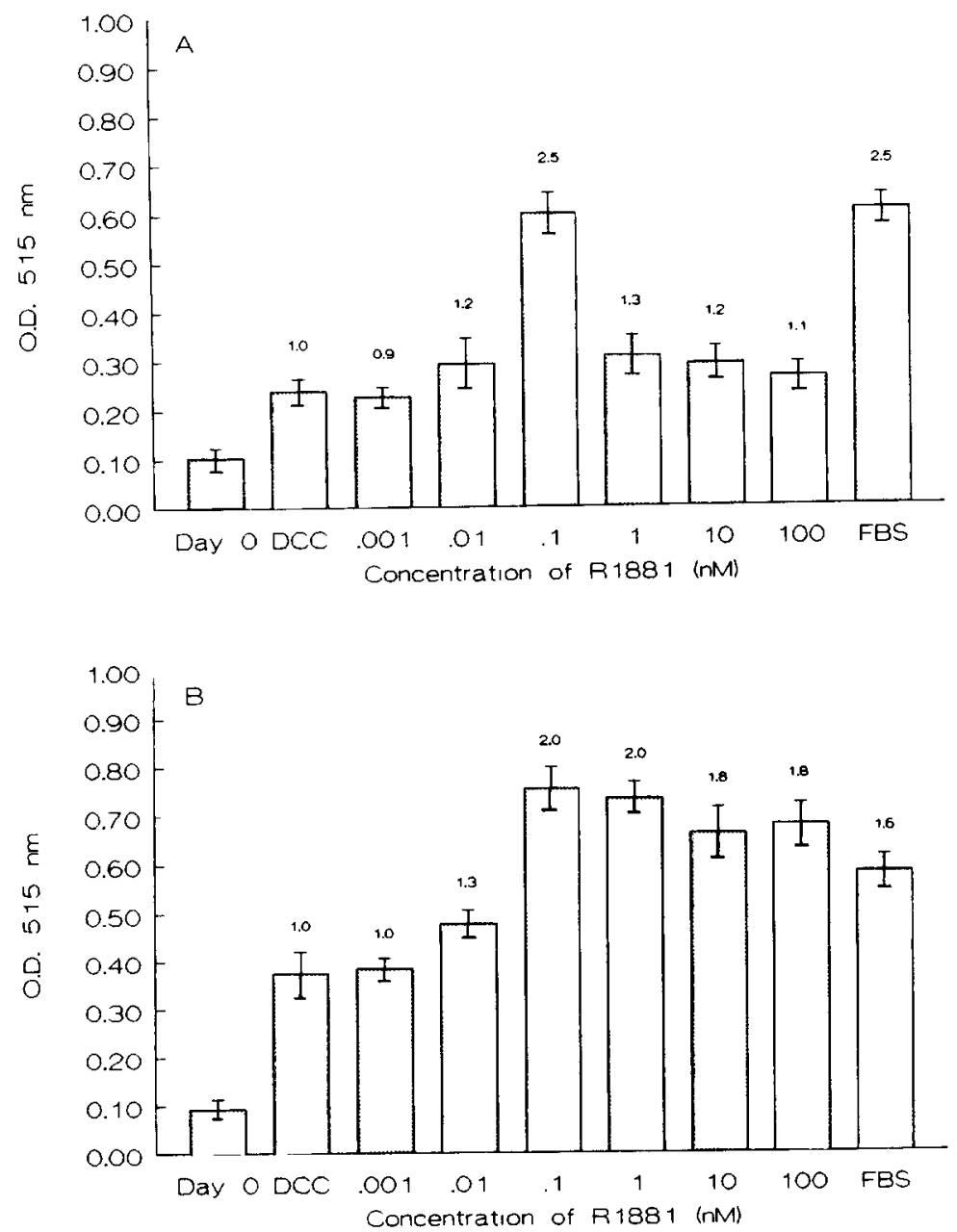

Fig. 3. MTT assay for dose-response for FGC (A) and FGC-DCC (B) cells grown in complete (FBS) or steroid-depleted (DCC) medium, substituted with different concentrations of the synthetic androgen R1881. 
stimulated at concentrations of $0.1-100 \mathrm{nM}$ $\mathrm{R} 1881$, whereas the response pattern of the parental FGC cell clearly showed an optimum at $0.1 \mathrm{nM}$.

\section{Growth properties of the FGC-JB subline}

The FGC-derived subline, FGC-JB, although like the parent FGC line androgen-sensitive, exhibited a slightly different pattern of responsiveness (Fig. 4). Generally, growth of FGC-JB cell was less optimal: in comparison with the FGC line, JB cells detach more easily from the culture plastic and these cells had a slower growth rate. In contrast to the FGC cells (Fig. 4, left panel), neither during a 3-day period of preconditioning the JB cells, nor during the subsequent 6 days of culturing these cells in DCC medium, could any increase of the cell number be found (Fig. 4, right panel). Independent of the baseline (no steroid) response to the DCC medium, for both the FGC and the FGCJB subline an approx. 2-fold increase of the cell number was obtained with $0.1 \mathrm{nM}$ R1881.

\section{Growth properties of the LNCaP-r (R) line}

Figure 5 shows the result of an experiment (based upon an MTT assay) in which the responsiveness of the FGC and the $\mathrm{R}$ line were compared. Growth of both the FGC and R line was stimulated when grown in DCC medium (3.2- and 4.5-fold, respectively). In contrast to the FGC cells, however, the $\mathrm{R}$ cells could not significantly be stimulated further by DCC medium with $\mathrm{R} 1881(0.1 \mathrm{nM})$, or by medium containing normal serum (FBS) (Fig. 5B). In fact, the $R$ cells could be grown equally well in medium with either DCC, DCC + R1881, or FBS. In this experiment it was also proven that neither the FGC cell, nor the $\mathrm{R}$ cell when grown in FBS containing medium, could be further stimulated with the optimal concentration $(0.1 \mathrm{nM})$ of R1881 (Fig. 5A and B).

\section{DISCUSSION}

There has always been a need for the development of hormone responsive model systems for human prostate cancer. Examples of hormone dependent human prostate carcinoma in vivo are the transplantable PC-82, PC-EW and Honda tumors, as reviewed in Ref. [18]. These well characterized tumors were hetero-transplanted directly into nude mice, but lack the property of continuous growth in vitro. Up to now, $\mathrm{LNCaP}$ is the only androgen-dependent prostatic cell line established in vitro. Hence, it offers the possibility to study the involvement of (steroid) hormones and other factors in growth and differentiation of prostatic cancer cells under culture conditions.

The FGC line, which directly descended from the $\mathrm{LNCaP}$ cell line, that was initially developed

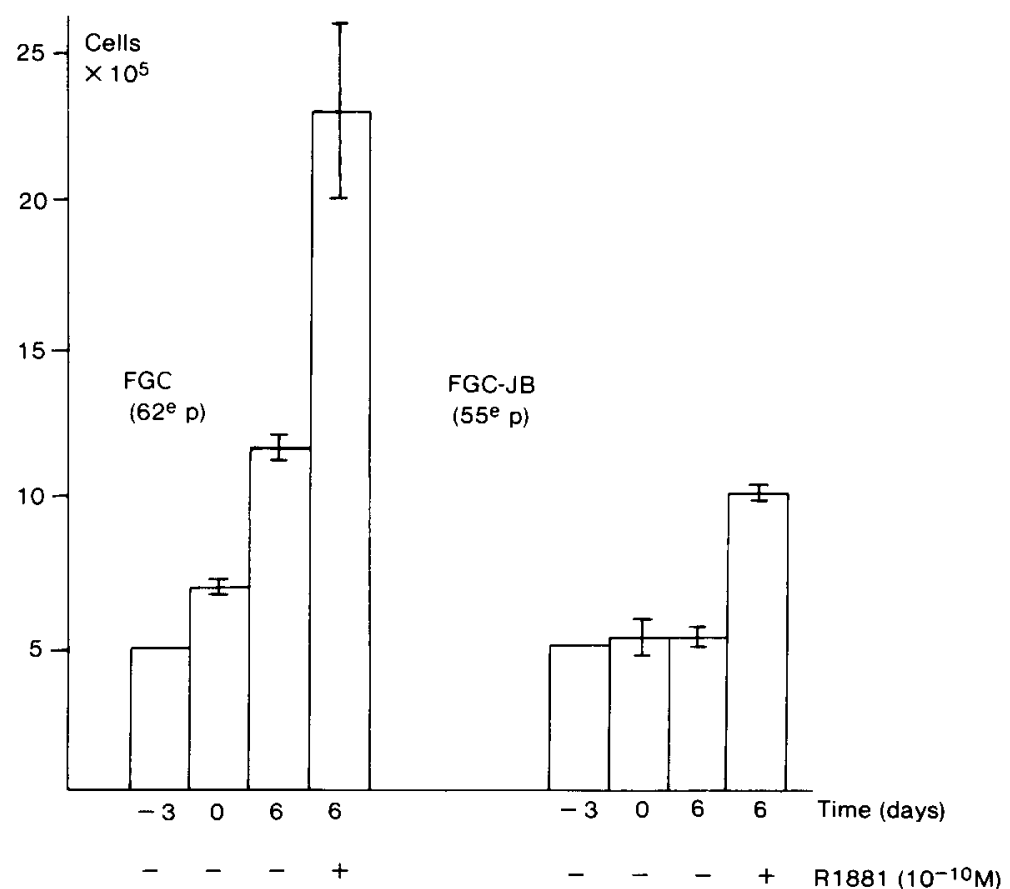

Fig. 4. Androgen responsiveness of the FGC and the FGC-JB cells in the presence of medium with or without $10^{-10} \mathrm{M}$ R 1881 . 
from the patient material (Fig. 1), retained all the main properties of the original LNCaP $[8,9]$. This cell line, which was distributed over a large number of institutes, is the subject of an increasing number of different studies. Meanwhile, a number of sublines have been developed which either arose spontaneously from the parental line, or which were obtained by prolonged culturing of the FGC line in steroid-depleted medium. Generally, the application of LNCaP and its derived sublines should be preceded by their careful characterization, in particular with respect to their hormone-dependent growth. It is recommended to carefully assess the appropriate culture conditions, especially when FGC cells are transferred from one laboratory to the other. Successful propagation of $\mathrm{LNCaP}$ cells strongly depends upon the culture conditions, such as the serum (batch) used, the type of culture plastic and the enzyme(s) used to subcultivate the cells, moreover, the cells appeared to be rather susceptible to mechanical disruption.

The present contribution describes the origin of the LNCaP subline, LNO and of the FGC sublines, FGC-JB, FGC-DCC and R (cf. Fig. 1). Except for the FGC-DCC line, the LNCaP-derived sublines of the present study were previously studied by König et al. [19] with respect to their cytogenetical characteristics. Clearly, the basic karyotype of the parental LNCaP cell line [20] was well preserved, which means that all sublines showed the same karyotypic evolutionary pattern. This comprises a doubling of the stem line to a near-tetraploid cell population, preservation of the original markers, and generation of some new, subline specific marker chromosomes [19].

The growth behavior of all $\mathrm{LNCaP}$ sublines was studied in steroid-depleted (DCC) and in androgen-substituted medium, the results being summarized in Table 1. FGC-JB appeared to be
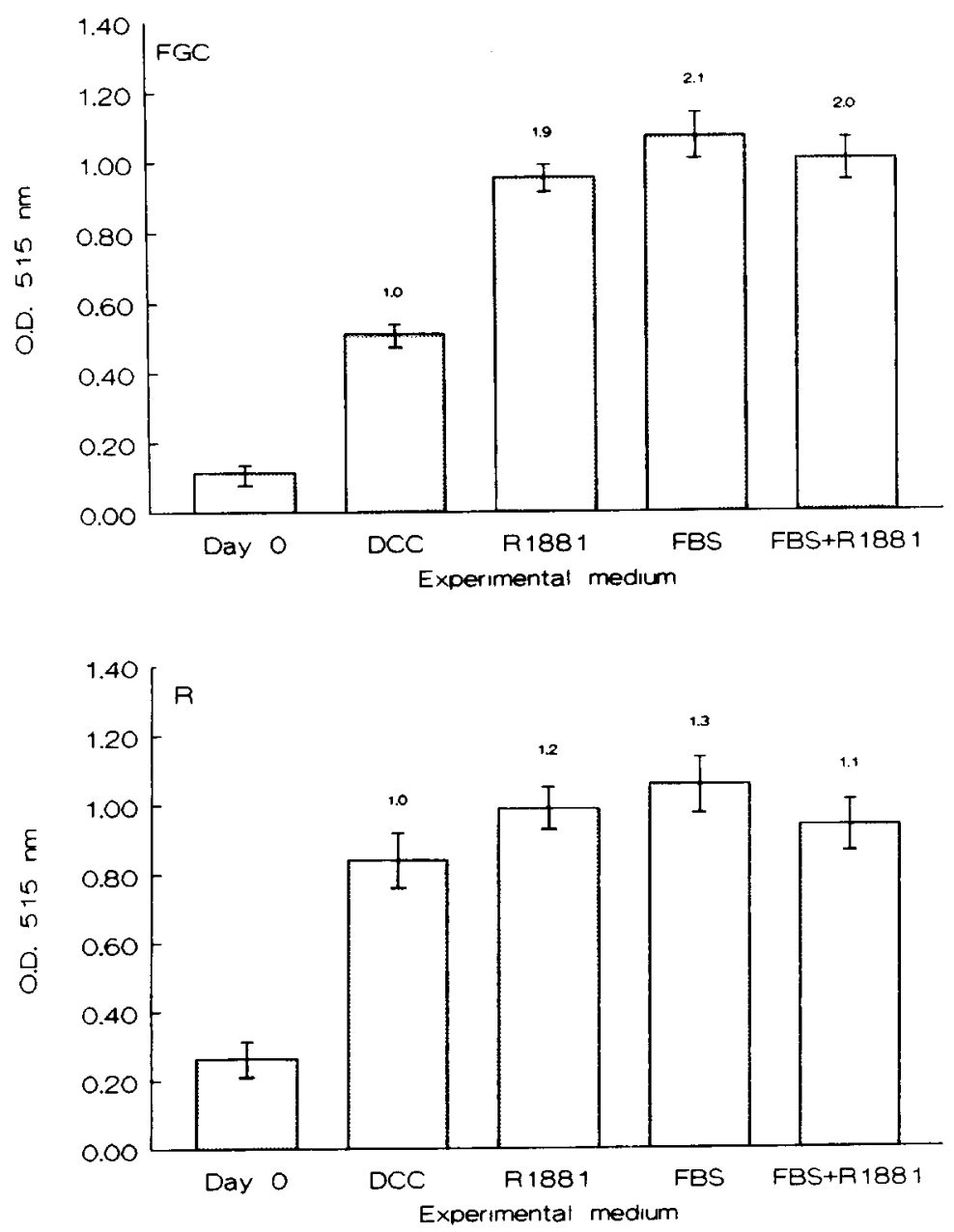

Fig. 5. MTT assay for growth of FGC cells (upper panel) and R cells (lower panel) in complete (FBS) and (DCC) medium with and without the synthetic androgen R1881. 
Table 1. Growth properties of several sublines of the LNCaP in vitro model

\begin{tabular}{|c|c|c|c|}
\hline \multirow[b]{2}{*}{ Subline } & \multicolumn{2}{|c|}{ Growth } & \multirow{2}{*}{$\begin{array}{c}\text { Response to } \\
\text { androgen } \\
\text { (R1881) }\end{array}$} \\
\hline & FBS & FBS-DCC & \\
\hline FGC & ++ & + & ++ \\
\hline FGC-DCC & + & ++ & ++ \\
\hline FGC-JB & + & - & + \\
\hline LNO & ++ & ++ & ND \\
\hline $\mathbf{R}$ & $t+$ & $+t$ & - \\
\hline
\end{tabular}

the only line that can not permanently be maintained in medium with DCC serum (Fig. 4). Long-term cultures (up to 6 months) of FGC cells in DCC medium i.e. in the absence of androgens, did not result in growth of androgen-independent cells, although compared to the FGC line, the FGC-DCC cells showed a slightly different pattern of androgen (R1881) responsiveness (Fig. 3). Apparently, under these conditions the hormone-dependent phenotype of this cell line is rather stable. For more conclusive results, however, growth of the cells under these circumstances should be followed for longer periods of time. Moreover, it was observed that FGC cells cultured in medium with complete (FBS) serum for more than 30 passages gradually showed a better growth response in DCC medium (result not shown). A comparison between the growth of the parental FGC line and the $\mathrm{R}$ line showed a similar pattern of serum and androgen responsiveness (Fig. 5). With that respect, it can not be excluded that, finally, the $\mathrm{R}$ line arose from a long-term culture of the FGC line [14]. It can be concluded that under the condition of long-term maintainance of the FGC cells, an increase of the basal growth rate without steroid, rather than a reduced androgen-responsiveness was observed. Similar observations were made with estrogen-dependent ZR-75-1 and T-47-D human breast cancer cells [21].

A maximal growth response of all sublines tested was found for cultures in FBS medium (Figs 3 and 5, Table 1). This could not be further enhanced by adding an optimal concentration of $0.1 \mathrm{nM} \mathrm{R} 1881$ to these cultures. With this respect care should be taken with the interpretation of results obtained with LNCaP cells tested for androgen responsiveness in the presence of complete (i.e. androgen containing) serum, such as described for the $\mathbf{R}$ line by Hasenson et al. [14]. Such an approach can easily lead to misinterpretation of the results obtained. In the present study $\mathrm{LNCaP}$ cells were cultured for at least 3 days in DCC medium prior to testing their serum or androgen responsiveness. Although in some studies dihydrotestosterone (DHT) was shown to be stimulatory for LNCaP cells [11], care should also be taken for the application of this androgen, as it was previously shown by Berns et al. [22] that both testosterone (T) and DHT were rapidly metabolized by LNCaP cells. Therefore, in the present study the non-metabolizable androgen R1881 [14] was used for testing androgen responsiveness of the $\mathrm{LNCaP}$ sublines.

Steroid-depleted (DCC) serum has extensively been used in studies on cell growth and response of hormone-sensitive cell lines [23, 24]. Although essential for preconditioning the LNCaP cells in hormone-sensitivity tests of the present study, the use of charcoal-treated serum is of limited value as it is not only depleted of steroids, but most likely also of growth factors and lipoproteins. Hence, there is a great need for the development of serum-free methods of culturing the LNCaP cells, such as described for other prostate cell lines by Kaighn et al. [25]. For a better and more reliable determination of the effects of hormones and growth factors on LNCaP growth in vitro, the use of defined media is a obligatory step in further studies with the LNCaP model. From our own experience and from other investigations [11] it became clear that at least for attachment to the plastic of the culture dish, LNCaP cells should necessarily be cultured for $24 \mathrm{~h}$ in serum supplemented medium. Once attached, LNCaP cells could be tested for androgen and growth factor responsiveness in a serum-free culture medium [11].

In conclusion, the $\mathrm{LNCaP}$ cell line and its derived sublines provide a suitable in vitro model for the study of several aspects of androgen responsiveness in human prostate cancer. Investigations into the role of growth factors and their receptors, will further elucidate the mechanism of androgen stimulated growth of LNCaP cells. Comparative studies, including detailed cytogenetical characterization of the various sublines, should yield valuable information concerning the development of androgen resistance in human prostate cancer.

Acknowledgements - The work reported in this manuscript was supported by the Dutch Cancer Society (KWF) through Grants IKR 87-8 and 90-13.

\section{REFERENCES}

1. Dexter D. L. and Calbresi P.: Intraneoplastic diversity. Biochem. Biophys. Acta 695 (1982) 97-112. 
2. Noble R. L.: Hormonal control of growth and progression in tumors of $\mathrm{Nb}$ rats and a theory of action. Cancer Res. 37 (1977) 82-94.

3. Noble R. L.: Tumor progression-endocrine regulation and control. In Drug and Hormone Resistance in Neoplasia (Edited by N. Bruchovsky and Goldie J, H.). C.R.C. Press, Boca Raton, FL, U.S.A. (1982) pp. $157-183$.

4. Blackard C. E.: The Veterans' Administration Cooperative Urological Research group studies of carcinoma of the prostate: a review. Cancer Chemother. Rep. 59 (1975) 225-227.

5. Menon M. and Walsh P. C.: Hormonal therapy for prostate cancer. In Prostatic Cancer (Edited by G. P. Murphy). Publishing Comp. Inc., Littleton, MA, U.S.A. (1979) pp. 175-200

6 Dickson R. B., Thompson E. W. and Lippman M. E.: Regulation of proliferation, invasion and growth factor synthesis in breast cancer. J. Steroid Biochem. Molec. Biol. 37 (1990) 305-316.

7. Murphy C. S., Pink J. J. and Jordan V. C.: Characterization of a receptor-negative, hormone-unresponsive clone derived from a T47D human breast cancer cell line kept under estrogen-free conditions. Cancer Res. 50 (1990) 7285-7292.

8. Horoszewicz J. S., Leong S. S., Chu T., Wajsman Z., Friedman M., Papsidero L., Kim U., Chiu L., Kakati S., Arya S. and Sandberg A. A.: The LNCaP cell line - a new model for studies on human prostatic carcinoma. Prog. Clin. Biol. Res. 37 (1980) 115-132.

9. Horoszewicz J. S., Leong S. S., Kawinski E., Karr J., Rosenthal H., Chu T. M., Mirand E. A. and Murphy G. P.: LNCaP model of human prostatic carcinoma. Cancer Res. 43 (1980) 1809-1818.

10. Schuurmans A. L. G., Bolt J., Voorhorst M., Blankenstein M. A. and Mulder E.: Regulation of growth and epidermal growth factor receptor levels of $\mathrm{LNCaP}$ prostate tumor cells by different steroids. Int. J. Cancer 42 (1988) 917-922.

11. Connolly J. M. and Rose D. P.: Production of epidermal growth factor and transforming growth factor- $\alpha$ by the androgen-responsive LNCaP human prostate cancer cell line. Prostate 16 (1990) 209-218.

12. Schuurmans A. L. G., Bolt J. and Mulder E.: Androgens stimulate both growth rate and epidermal growth factor receptor activity of the human prostate tumor cell. Prostate 12 (1988) 55-63.

13. Schuurmans A. L. G., Bolt J., Veldscholte J. and Mulder E.: Regulation of growth of LNCaP human prostate tumor cells by growth factors and steroid hormones. J. Steroid Biochem. Molec. Biol. 40 (1991) 193-197.
14. Hasenson M., Hartley-Asp B., Kihlffors C., Lundin A., Gustafsson J. and Pousette A.: Effect of hormones on growth and ATP content of a human prostatic carcinoma cell line, LNCaP-r. Prostate 7 (1985) 183-194.

15. Bonne C. and Raynaud J. P.: Methyltrienolone, a specific ligand for cellular androgen receptors. Steroids 26 (1976) 227-232.

16. Mosmann T.: Rapid colorimetric assay for cellular growth and survival: application to proliferation and cytotoxicity assays. J. Immun. Meth. 65 (1983) 55-63.

17. Romijn J. C., Verkoelen C. F. and Schroeder F. H.: Application of the MTT assay to human prostate cancer cell lines in vitro: establishment of test conditions and assessment of hormone-stimulated growth and druginduced cytostatic and cytotoxic effects. Prostate $\mathbf{1 2}$ (1988) 99-110.

18. van Steenbrugge G. J.: Transplantable human prostate cancer (PC-82) in athymic nude mice: a model for the study of androgen-regulated tumor growth. Ph.D. Thesis, Rotterdam (1988).

19. König J. J., Kamst E., Hagemeijer A., Romijn J. C., Horoszewicz J. J. and Schröder F. H.: Cytogenetic characterization of several androgen responsive and unresponsive sublines of the human prostatic carcinoma cell line LNCaP. Urol. Res. 17 (1989) 79-86.

20. Gibas Z., Becher R., Rawinski E., Horoszewicz J. J. and Sandberg A. A.: A high resolution study of chromosomal changes in a human prostatic carcinoma cell line (LNCaP). Cancer Genet. Cytogenet. 11 (1984) 399-404.

21. Daly R. L. and Darbre P. D.: Cellular and molecular events in loss of estrogen sensitivity in ZR-75-1 and T-47-D human breast cancer cells. Cancer Res. 50 (1990) 5868-5875.

22. Berns E. M. J. J., de Boer W. and Mulder E.: Androgen dependent growth of and the release of specific protein(s) by the androgen receptor containing human prostate tumor cell line LNCaP. Prostate 9 (1986) 247-259.

23. Butler W. B., Kelsey W. H. and Goran N.: Effects of serum and insulin on the sensitivity of the human breast cancer cell line MCF-7 to estrogen and antiestrogen. Cancer Res. 41 (1981) 82-88.

24. Page M. J., Field J. K., Everett N. P. and Green C. D. Serum regulation of the estrogen responsiveness of the human breast cancer cell line MCF-7. Cancer Res. 43 (1983) 1244-1250.

25. Kaighn M. E., Kirk D., Szalay M. and Lechner J. F. Growth control of prostatic carcinoma cell in serumfree media: interrelationship of hormone response, cell density, and nutrient media. Proc. Natn. Acad. Sci. U.S.A. 78 (1981) 5673-5676. 